\title{
Concentrations, profiles and gas-particle partitioning of PCDD/Fs, PCBs and PBDEs in the ambient air of an E-waste dismantling area, southeast China
}

\author{
LI YingMing, JIANG GuiBin, WANG YaWei, WANG Pu \& ZHANG QingHua' \\ State Key Laboratory of Environmental Chemistry and Ecotoxicology, Research Center for Eco-Environmental Sciences, Chinese \\ Academy of Sciences, Beijing 100085, China
}

Polychlorinated diebenzo-p-dioxins (PCDDs), polychlorinated diebenzofurans (PCDFs), polychlorinated biphenyls (PCBs) and polybrominated diphenyl ethers (PBDEs) were monitored in the ambient air of Taizhou, an E-waste dismantling area of southeast China to evaluate their concentrations, profiles and gas-particle partitioning. The $\Sigma P C D D / F s$ concentrations ranged from 2.91 to $50.6 \mathrm{pg} / \mathrm{m}^{3}$, with an average of $14.3 \mathrm{pg} / \mathrm{m}^{3}$. The I-TEQs for PCDD/Fs were in the range of $0.20-3.45 \mathrm{pg} / \mathrm{m}^{3}$, with an average of $1.10 \mathrm{pg} / \mathrm{m}^{3}$. The $\Sigma P C B s$ concentrations and TEQs ranged from 4.23 to $11.35 \mathrm{ng} / \mathrm{m}^{3}, 0.050$ to 0.859 $\mathrm{pg}(T E Q) / \mathrm{m}^{3}$, respectively. The concentrations of $\Sigma P B D E s$ ranged from 92 to $3086 \mathrm{pg} / \mathrm{m}^{3}$, with an average of $894 \mathrm{pg} / \mathrm{m}^{3}$. The pollution levels of PCDD/Fs, PCBs and PBDEs were higher than other urban sites, which may be associated with the E-waste dismantling activities. The PCDD/Fs were found exclusively in the particle phase whereas PCBs distributed dominantly in the gas phase. The gas-partilce partitioning was also assessed by correlating the gas-particle partition coefficient $\left(K_{\mathrm{p}}\right)$ with the subcooled liquid vapor pressure $\left(P_{\mathrm{L}}{ }^{0}\right)$. The measured particulate sorptions of PCDD/Fs, PCBs and PBDEs were compared with the predictions from Junge-Pankow model and $K_{\text {oa }}$ absorption model. The Junge-Pankow model well estimated the particulate fractions of PCBs. However, it underestimated the sorptions of PCDD/Fs and overestimated the fractions of PBDEs. The predicted particulate fractions of PCDD/Fs and PCBs from $K_{\text {oa }}$ model fitted well with the measured data.

PCDD/Fs, PCBs, PBDEs, air, gas-particle partitioning, E-waste

Polychlorinated dibenzo- $p$-dioxins (PCDDs), polychlorinated dibenzofurans (PCDFs) and polychlorinated biphenyls (PCBs) are three groups of persistent organic pollutants (POPs) that are stable in the environment, accumulate in the fatty tissue of living organisms and undergo long range transports. $\mathrm{PCDD} / \mathrm{Fs}$ were not intentionally manufactured. They were formed or released to the environment from various combustion activities and productions of chlorinated chemicals as byproducts. PCBs were historically synthesized and used as dielectric fluid transformers and capacitors. Polybrominated diphenyl ethers (PBDEs) are used as flame retardant in plastics, textiles and electronics. The commercial PBDEs products mainly include penta-BDE, octa-
BDE and deca-BDE. Because they show similar physical-chemical properties to some other POPs, PBDEs are recognized as emerging environmental pollutants in recent years. The environmental fate and transport pathways of these chemical pollutants are continually concerned because of their potential exposure to humans.

Atmosphere is a major pathway for these chemical pollutants to transport and redistribute in the environment. PCDD/Fs, PCBs and PBDEs exist between the gas phase and particle phase in the ambient air. It is es-

\footnotetext{
Received August 30, 2007; accepted October 15, 2007 doi: 10.1007/s11434-008-0125-8

Corresponding author (email: qhzhang@rcees.ac.cn)

Supported by the National Natural Science Foundation of China (Grant No. 20607025, 20777079 and 20737007)
} 
sential for us to knowledge about the gas-particle partitioning since it affects their transport pathways, degradation mechanisms, deposition processes and mode of entry into food chains ${ }^{[1]}$. However, few studies were carried out for measuring and predicting their levels and partitioning in the ambient air in China ${ }^{[2,3]}$.

Taizhou situates in the southeast coastline of China. In the 1980s, the dismantling operations of E-wastes emerged and boomed in some towns of Taizhou. The scrap transformers containing PCBs as dielectric fluids were once dismantled in this area. Until now, most of E-wastes are still simply dismantled or incinerated openly to remove PVC coating to retrieve valuable metals. These activities resulted in environmental pollutions of PCDD/Fs and PCBs ${ }^{[4,5]}$. The aim of this study was to monitor PCDD/Fs, PCBs and PBDEs in the ambient air of the typical E-waste dismantling area in Taizhou to evaluate their concentrations, profiles and gas-particle distributions. By analyzing the gas-particle partitioning of these pollutants, their environmental fate and transportation were also discussed.

\section{Materials and methods}

\subsection{Sampling}

The climate of Taizhou belongs to typical sub-tropical monsoon, which is characteristic with rich rainfalls (annual volume from 1480 to $1530 \mathrm{~mm}$ ) and year-round temperatures from 16.9 to $17.3^{\circ} \mathrm{C}$. Sampling site A $\left(121^{\circ} 21.731^{\circ} \mathrm{E}, 28^{\circ} 32.724^{\circ} \mathrm{N}\right)$ and $\mathrm{C}\left(121^{\circ} 21.672^{\circ} \mathrm{E}\right.$, $28^{\circ} 32.772^{\circ} \mathrm{N}$ ) are rural areas and in two residential villages of the town. Site B $\left(121^{\circ} 21.675^{\circ} \mathrm{E}, 28^{\circ} 32.755^{\circ} \mathrm{N}\right)$ situates in the commercial center of the dismantling town besides the Road 104 .

Air samples were concurrently collected in sites A, B and $\mathrm{C}$ for an interval of 12 hours by using high volume air samplers (GPS1, Thermo Environmental Instruments, Inc., Franklin, MA). The average temperature and PM10 data during the sampling period were $16.9^{\circ} \mathrm{C}$ and 90 $\mu \mathrm{g} / \mathrm{m}^{3}$, respectively. The sampling process was conducted according to US EPA Compendium Method TO9A. Briefly, the sampler was equipped with a quartz fiber filter for sampling particle-bound pollutants, following by a glass cartridge with PUF $(6.3 \mathrm{~cm}$ diameter, $7.6 \mathrm{~cm}$ length) contained in the glass cartridge for sampling gas phase chemicals. Prior to sampling, the quartz fiber filters (Whatman, $10.16 \mathrm{~cm}$ diameter) were baked at $450^{\circ} \mathrm{C}$ for $12 \mathrm{~h}$ to remove any organic contaminants.
The PUFs were followed with a 24-h extraction with acetone and another 24-hour extraction with hexane. Then, the sampling cartridges were vacuum-dried in desiccators and stored in sealed bags.

The airflow rate was specified at $0.25 \mathrm{~m}^{3} / \mathrm{min}$ at the beginning of sampling. After sampling, the GFF and PUF plug were wrapped with hexane-rinsed aluminum foil for protection from light, and stored in sealed bags. After transported to the laboratory, they were stored at $-20^{\circ} \mathrm{C}$ until analysis.

\subsection{Sample analysis}

All the organic solvents were pesticide residue grade from Fisher (Fair Lawn, NJ, USA). Silica was purchased from Merck (silica gel 60, Darmstadt, Germany). Basic alumina was obtained from Aldrich (Brockmann I, standard grade, Milwaukee, USA). Florisil was from Riedel-deHaën (60 - 100 mesh, Seelze, Germany). Calibration standard solutions, ${ }^{13} \mathrm{C}_{12}$-labeled surrogate standards and ${ }^{13} \mathrm{C}_{12}$-labeled injection standards were purchased from Wellington Laboratories (Guelph, Canada).

Prior to a $24 \mathrm{~h}$ Soxhlet extraction with toluene, filters or PUFs were spiked with 15 congeners of ${ }^{13} \mathrm{C}_{12}$-labeled surrogate standards for PCDD/Fs. Also $27 \mathrm{PCB}$ congeners of ${ }^{13} \mathrm{C}_{12}$-labeled surrogate standards for PCBs, ${ }^{13} \mathrm{C}$-BDE-47, ${ }^{13} \mathrm{C}$-BDE-99 and ${ }^{13} \mathrm{C}-\mathrm{BDE}-153$ were incorporated for the determination of PCBs and PBDES, respectively. The extract was subsequently refluxed in hexane and subjected to a multilayer silica gel column, followed by clean-up on basic alumina column and florisil chromatography columns. The detailed clean-up procedure was described elsewhere ${ }^{[6]}$. Prior to HRGCHRMS analysis, the exact was spiked with the ${ }^{13} \mathrm{C}_{12}$ labeled internal standard $\left({ }^{13} \mathrm{C}-1,2,3,4-\mathrm{TCDD}\right.$ and ${ }^{13} \mathrm{C}-1$, 2,3,7,8,9-HxCDD for PCDD/Fs; ${ }^{13} \mathrm{C}-\mathrm{PCB}-9,52,101$, 138 and ${ }^{13} \mathrm{C}-\mathrm{PCB}-194$ for $\mathrm{PCBs} ;{ }^{13} \mathrm{C}-\mathrm{PCB}-138$ for PBDEs) for recovery quantification.

The PCDD/Fs, PCBs and PBDEs were quantified on Agilent 6890 gas chromatography coupled with an Autospec Ultima high resolution mass spectrometer with an electron impact (EI) ion source. The HRMS was operated in SIR mode at $R \geqslant 10000$. Exactly $1 \mu \mathrm{L}$ of sample solution was injected with a CTC PAL autosampler in splitless mode into a DB-5 fused silica capillary column (60 m for PCDD/Fs and PCBs, $30 \mathrm{~m}$ for PBDEs). Helium served as the carrier gas with a constant flow of 
$1.2 \mathrm{~mL} / \mathrm{min}$. The electron emission energy was set to 35 $\mathrm{eV}$, and the source temperature was $270^{\circ} \mathrm{C}$. The oven temperature programs were employed as follows: for $\mathrm{PCDD} / \mathrm{Fs}$, start $150^{\circ} \mathrm{C}$ held for $3 \mathrm{~min}, 150-230^{\circ} \mathrm{C}$ at $20^{\circ} \mathrm{C} / \mathrm{min}$ held for $18 \mathrm{~min}, 230-235^{\circ} \mathrm{C}$ at $5^{\circ} \mathrm{C} / \mathrm{min}$ held for $10 \mathrm{~min}, 235-320^{\circ} \mathrm{C}$ at $4{ }^{\circ} \mathrm{C} / \mathrm{min}$ held for $3 \mathrm{~min}$; for PCBs, start $120^{\circ} \mathrm{C}$ held for $1 \mathrm{~min}, 120-150^{\circ} \mathrm{C}$ at $30^{\circ} \mathrm{C} / \mathrm{min}, 150-300^{\circ} \mathrm{C}$ at $2.5^{\circ} \mathrm{C} / \mathrm{min}$ held for $1 \mathrm{~min}$; for PBDEs, start $100^{\circ} \mathrm{C}$ held for $2 \mathrm{~min}, 100-230^{\circ} \mathrm{C}$ at $15^{\circ} \mathrm{C} / \mathrm{min}, 230-270^{\circ} \mathrm{C}$ at $5^{\circ} \mathrm{C} / \mathrm{min}, 270-330^{\circ} \mathrm{C}$ at $10^{\circ} \mathrm{C} / \mathrm{min}$ held for $8 \mathrm{~min}$.

\subsection{Quality assurance and quality control}

Three pairs of field blanks and laboratory blanks were incorporated in the analytical procedure for the purpose of quality control. There was no apparent difference between field blanks and laboratory blanks. OCDD, $1,2,3,4,6,7,8-\mathrm{HpCDD}, \mathrm{PCB}-28$ and BDE-47 were the main contaminants in the blanks. However, their concentrations in blanks corresponded to $<5 \%$ of the concentrations detected in the air samples. A breakthrough test was made by using a second half PUF in series with the first PUF and no breakthrough was found. The sample recoveries for ${ }^{13} \mathrm{C}$-OCDD were $38-98 \%$. The recoveries for other ${ }^{13} \mathrm{C}$ labeled PCDD/Fs were $55-125 \%$. The recoveries for ${ }^{13} \mathrm{C}$ labeled $\mathrm{PCB}$ were $31-120 \%$. Recoveries for ${ }^{13} \mathrm{C}-\mathrm{BDE}-47,99$ and ${ }^{13} \mathrm{C}-\mathrm{BDE}-153$ were $41 \%-109 \%, 40 \%-117 \%, 35 \%-124 \%$, respectively. All the sample recoveries were complied with US EPA method 1613, method 1668 and method 1614. The de- tection limits were $0.003-0.014 \mathrm{pg} / \mathrm{m}^{3}$ for $\mathrm{PCDD} / \mathrm{Fs}$, $0.010-0.063 \mathrm{pg} / \mathrm{m}^{3}$ for PCBs, and $0.014-0.148 \mathrm{pg} / \mathrm{m}^{3}$ for PBDEs except BDE-209 whose detection limits were $4.55 \mathrm{pg} / \mathrm{m}^{3}$.

\section{Results and discussion}

\subsection{Concentrations and profiles}

The concentrations and I-TEQ values of 2,3,7,8-substituted PCDD/Fs during the sampling period are shown in Table 1. The $\Sigma \mathrm{PCDD} /$ Fs concentrations ranged between 2.91 and $50.6 \mathrm{pg} / \mathrm{m}^{3}$, with an average of $14.3 \mathrm{pg} / \mathrm{m}^{3}$. Figure 1(a) shows the $\mathrm{PCDD} / \mathrm{F}$ profiles for the three sampling sites. The congeners $\mathrm{HxCDF}, \mathrm{HpCDF}$ and OCDD contributed dominantly to the $\sum \mathrm{PCDD} / \mathrm{Fs}$ concentrations. The PCDD concentrations increased with the increase of chlorinated level, which was consistent with the general trend reported in previous studies ${ }^{[7]}$. However, the PCDFs were contrary to the trend for decreasing concentrations with increasing levels of chlorination.

The TEQ values were calculated according to the International Toxicity Equivalency Factor (I-TEF) [International toxicity equivalency (I-TEF) method of risk assessment for complex mixtures of dioxins and related compounds. Pilot study on international information exchange on dioxins and related compounds. Report No. 176, 1988]. The I-TEQs were in the range $0.20-3.45$ $\mathrm{pg} / \mathrm{m}^{3}$, with an average of $1.10 \mathrm{pg} / \mathrm{m}^{3}$. The congener $2,3,4,7,8-\mathrm{PeCDF}$ contributed dominantly to the total I-TEQs with an average of $46.2 \%$. Other significant

Table 1 Concentrations $\left(\mathrm{pg} / \mathrm{m}^{3}\right)$, TEQs $\left(\mathrm{pg}(\mathrm{TEQ}) / \mathrm{m}^{3}\right)$ of PCDD/Fs, PCBs and PBDEs

\begin{tabular}{|c|c|c|c|c|c|c|c|c|c|c|c|c|}
\hline Sample No. & A1 & $\mathrm{A} 2$ & $\mathrm{~A} 3$ & A4 & $\mathrm{B} 1$ & B2 & B3 & B4 & $\mathrm{C} 1$ & $\mathrm{C} 2$ & $\mathrm{C} 3$ & $\mathrm{C} 4$ \\
\hline Date & $28 / 10 / 05$ & $28 / 10 / 05$ & $29 / 10 / 05$ & $29 / 10 / 05$ & $28 / 10 / 05$ & $28 / 10 / 05$ & $29 / 10 / 05$ & $29 / 10 / 05$ & $28 / 10 / 05$ & $28 / 10 / 05$ & $29 / 10 / 05$ & $29 / 10 / 05$ \\
\hline Day or night & day & night & day & night & day & night & day & night & day & night & day & night \\
\hline Volume $\left(\mathrm{m}^{3}\right)$ & 103 & 184 & 109 & 228 & 90 & 197 & 114 & 201 & 142 & 184 & 121 & 201 \\
\hline$\Sigma$ PCDDs & 5.55 & 0.90 & 1.55 & 8.86 & 1.99 & 3.02 & 4.07 & 2.84 & 2.26 & 0.77 & 1.20 & 24.3 \\
\hline$\Sigma$ PCDFs & 11.8 & 2.02 & 9.48 & 19.3 & 3.20 & 13.1 & 1.85 & 17.8 & 3.55 & 2.98 & 2.59 & 26.2 \\
\hline$\Sigma$ PCDDs $/ \Sigma$ PCDFs & 0.47 & 0.44 & 0.16 & 0.46 & 0.62 & 0.23 & 2.20 & 0.16 & 0.64 & 0.26 & 0.46 & 0.93 \\
\hline$\Sigma \mathrm{PCDD} / \mathrm{Fs}$ & 17.3 & 2.91 & 11.0 & 28.2 & 5.19 & 16.1 & 5.91 & 20.6 & 5.81 & 3.75 & 3.80 & 50.6 \\
\hline I-TEQ for PCDD/Fs & 1.33 & 0.22 & 0.96 & 2.59 & 0.38 & 1.28 & 0.20 & 1.71 & 0.42 & 0.24 & 0.39 & 3.45 \\
\hline$\Sigma$ PCBs & 9906 & 5758 & 7603 & 6493 & 11352 & 6129 & 6459 & 7160 & 9452 & 4232 & 4762 & 7321 \\
\hline TEQ for PCBs & 0.195 & 0.064 & 0.116 & 0.347 & 0.178 & 0.206 & 0.078 & 0.243 & 0.108 & 0.05 & 0.069 & 0.859 \\
\hline TEQs for PCDD/Fs+PCBs & 1.53 & 0.29 & 1.08 & 2.93 & 0.56 & 1.48 & 0.28 & 1.95 & 0.52 & 0.29 & 0.46 & 4.31 \\
\hline$\Sigma$ PBDEs & 3086 & 224 & 92 & 702 & 728 & 243 & 445 & 2543 & 925 & 282 & 254 & 1201 \\
\hline BDE-209 & 3009 & 3079 & 415 & 1228 & 1308 & 59 & 1639 & 341 & 205 & 165 & 536 & 1231 \\
\hline
\end{tabular}



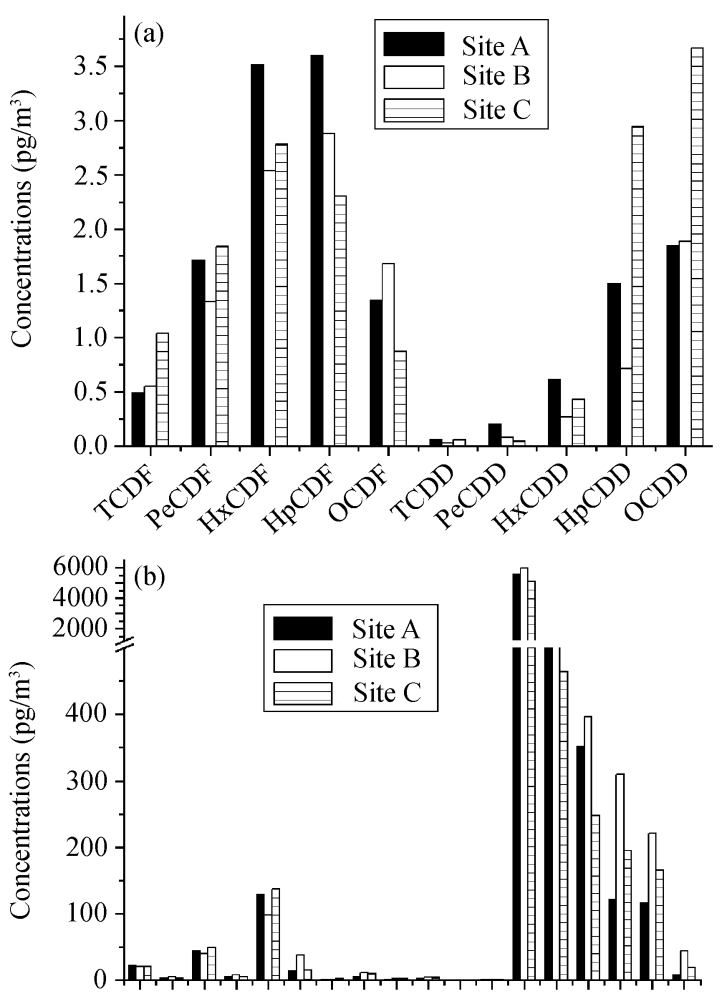

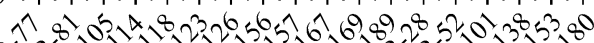

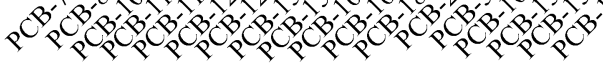

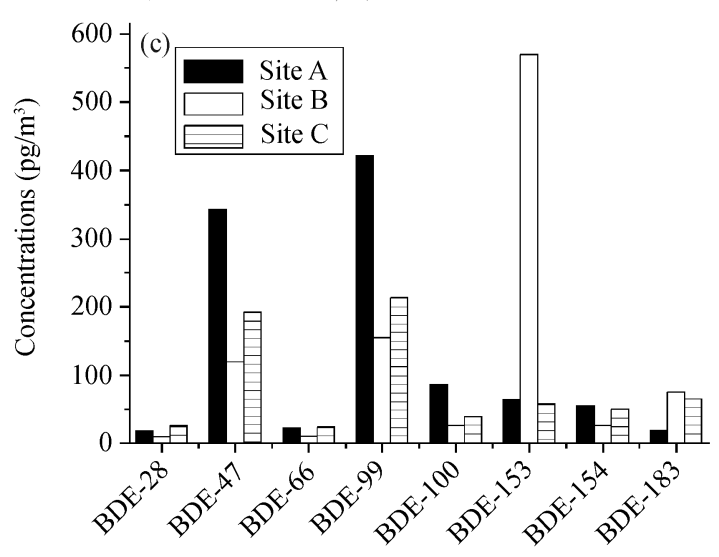

Figure 1 Profiles of PCDD/Fs, PCBs and PBDEs.

contributors to the total I-TEQ were as follows: 2,3,4, $6,7,8-\mathrm{HxCDF} \quad(\sim 9.7 \%), 1,2,3,6,7,8-\mathrm{HxCDF} \quad(\sim 7.5 \%)$, 1,2,3,4,7,8-HxCDF ( 6.5\%), 1,2,3,7,8-PeCDD ( 5.0\%). The I-TEQs in Taizhou air was higher than the general PCDD/Fs levels in the ambient air with $\sum$ TEQ $<10$ $\mathrm{fg} / \mathrm{m}^{3}$ for remote area, $\sim 20-50 \mathrm{fg}(\mathrm{TEQ}) / \mathrm{m}^{3}$ for rural area and $\sim 100-400 \mathrm{fg}(\mathrm{TEQ}) / \mathrm{m}^{3}$ for urban/industry $\operatorname{area}^{[8]}$.

The $\Sigma$ PCBs ranged from 4.23 to $11.35 \mathrm{ng} / \mathrm{m}^{3}$, with an average of $7.22 \mathrm{ng} / \mathrm{m}^{3}$. The TEQs conbributed by coplanar PCBs were calculated using World Health Or- ganizations Toxic Equivalent Factors ${ }^{[9]}$ and the values were in the range $0.050-0.859 \mathrm{pg}(\mathrm{TEQ}) / \mathrm{m}^{3}$ (average $\left.0.209 \mathrm{pg}(\mathrm{TEQ}) / \mathrm{m}^{3}\right)$. The results were higher than the atmospheric PCBs in other locations. For instance, the concentration of total PCB and TEQ ranged from 62 to $250 \mathrm{pg} / \mathrm{m}^{3}$ and from 2 to $14 \mathrm{fg}(\mathrm{TEQ}) / \mathrm{m}^{3}$, for Yokohama City, Japan ${ }^{[10]}$. Tasdemir reported the mean concentrations of $\Sigma_{50}$ PCBs ranged between 0.4 and $8.3 \mathrm{ng} / \mathrm{m}^{3}$ in the ambient air of Chicago ${ }^{[11]}$. The PCB profiles were shown in Figure 1(b) with the lighter congener PCB-28 dominating the profile patterns. Among coplanar PCBs, the congener PCB-118 presented the highest concentrations. However, the main contributor to $\Sigma$ TEQ was PCB-126, which was responsible for an average contribution of $85.5 \%$.

The $\Sigma$ PBDEs and BDE-209 concentrations are shown in Table 1. $\Sigma$ PBDEs refers to all the target PBDE congeners detected in the study except BDE-209. The concentrations of $\Sigma$ PBDEs ranged between 92 and 3086 $\mathrm{pg} / \mathrm{m}^{3}$, with an average of $894 \mathrm{pg} / \mathrm{m}^{3}$. BDE-209 was in the range 59-3079 $\mathrm{pg} / \mathrm{m}^{3}$ (average $1101 \mathrm{pg} / \mathrm{m}^{3}$ ). The $\Sigma$ PBDEs and BDE-209 concentrations were comparable to a large industrial zone in Guangzhou air, but higher than those from East-Central U.S. ${ }^{[3,12]}$. PBDEs were generally used as flame retardants for electric products. The activity of dismantling E-wastes increased or released PBDEs to the ambient air. BDE-209 was the dominant congener for the total PBDEs. The other main contributors were BDE-47 and BDE-99. The result was consistent with other reports ${ }^{[3]}$.

\subsection{Distribution in gas and particle phases}

The $\Sigma$ PCDD/Fs appeared to present exclusively in the particle phase, with average concentrations of 13.67 $\mathrm{pg} / \mathrm{m}^{3}$ in the aerosols and $0.94 \mathrm{pg} / \mathrm{m}^{3}$ in the gas phase. Figure 2 shows the relative gas-particle distribution of individual congeners. The heavier congeners were more associated with the particle phase, while the lighter congeners of TCDD/Fs tended to distribute in the gas phase. The results were consistent with the data in the ambient air of Huston ${ }^{[13]}$.

The partitioning trend of PCBs was contrary to that of PCDD/Fs. The $\Sigma$ PCBs concentrations (average 6932 $\mathrm{pg} / \mathrm{m}^{3}$ ) in the gas phase were dominantly higher than that in the particle phases (average $287 \mathrm{pg} / \mathrm{m}^{3}$ ). However, the gas-particle distribution of PCB congeners was also based on molecular weights, which was similar to that of PCDD/Fs. For instance, tri-CB (PCB-28) and tetra-CB 


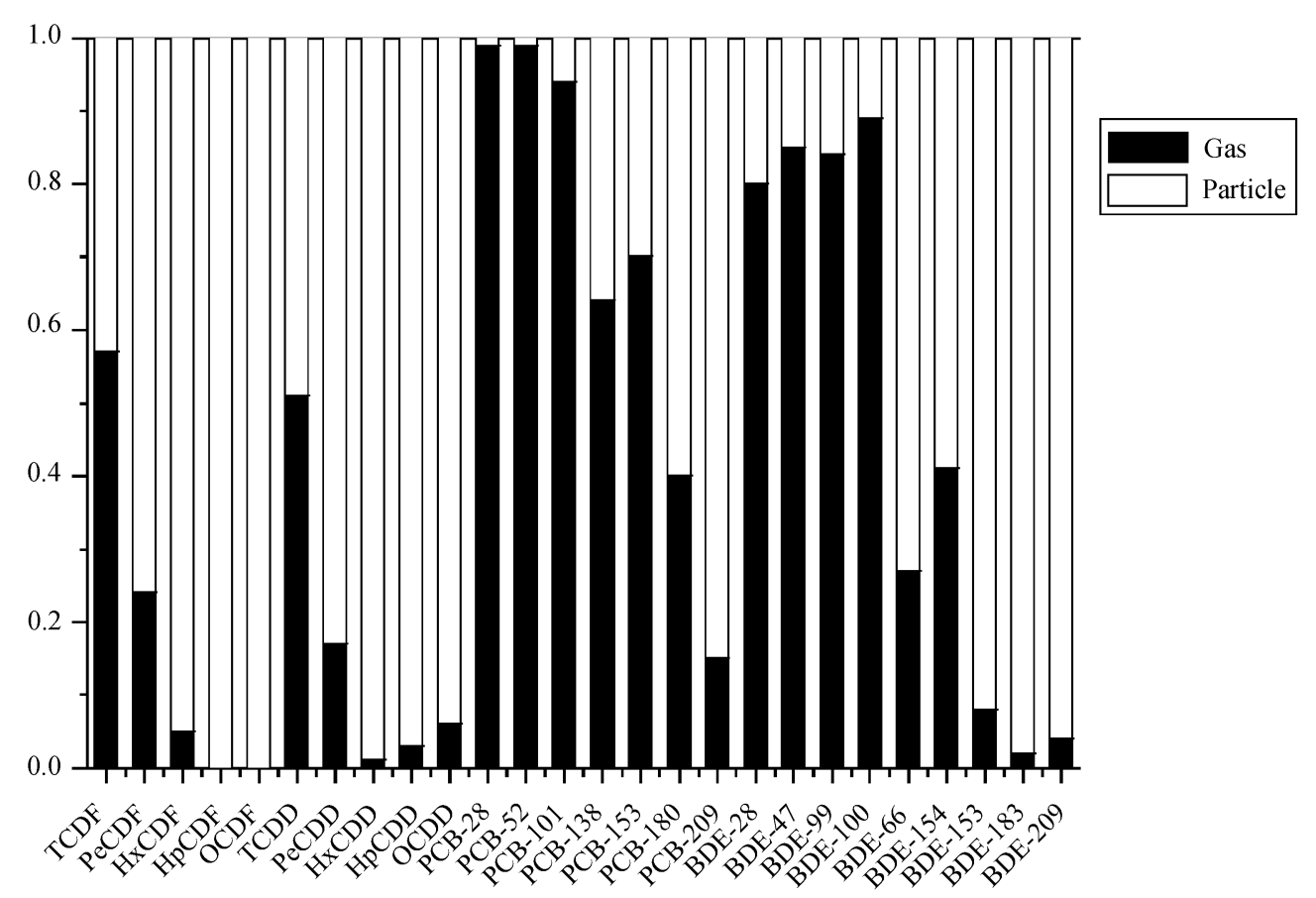

Figure 2 Relative distribution of PCDD/Fs, PCBs and PBDEs between gas phase and particle phase.

(PCB-52) presented dominantly in the gas phase whereas the deca-CB (PCB-209) was mainly found in the particle phase.

For 5 PBDEs and BDE-209, the average concentrations were $505 \mathrm{pg} / \mathrm{m}^{3}, 51 \mathrm{pg} / \mathrm{m}^{3}$ in the gas phase and 389 $\mathrm{pg} / \mathrm{m}^{3}, 1054 \mathrm{pg} / \mathrm{m}^{3}$ in the particle phase, respectively. Similar to the distribution pattern of PCDD/Fs and PCBs, the lighter congener BDE-28, 47 was mainly in the gas phase while the heavier congener BDE-209 existed dominantly in the particle phase.

The gas-particle partition coefficient $\left(K_{\mathrm{p}}\right)$ is common used to describe gas-particle partitioning of SVOCs by using $K_{\mathrm{p}}=(F / A) / \mathrm{TSP}$, where $F$ and $A\left(\mathrm{ng} / \mathrm{m}^{3}\right)$ are particle-associated and gaseous concentrations, respectively, and TSP $\left(\mu \mathrm{g} / \mathrm{m}^{3}\right)$ represents the total suspended particulate matter concentration ${ }^{[14]}$. Two mechanisms exist for the partitioning process i.e. adsorption into the surface area of aerosols and absorption into the organic matter. For both mechanisms, the partitioning information can be extracted from the regression of $\log K_{\mathrm{p}}$ against logarithm of the subcooled liquid vapor pressure $\left(P_{\mathrm{L}}{ }^{0}\right)$, i.e. $\log K_{\mathrm{p}}=m_{\mathrm{r}} \log P_{\mathrm{L}}^{0}+b_{\mathrm{r}}$. The slope should be close to -1 for either adsorption or absorption mechanism in true equilibrium state ${ }^{[15]}$. The intercept was mainly dependent on the type and properties of the aerosols.

Table 2 shows the regression data of $\log K_{\mathrm{p}}$ versus $\log$ $P_{\mathrm{L}}{ }^{0}$ for PCDD/Fs, PCBs and PBDEs. Previous studies
Table 2 Regression data of $\log K_{\mathrm{p}}$ versus $\log P_{\mathrm{L}}{ }^{0}$

\begin{tabular}{ccccc}
\hline & Slope $m_{\mathrm{r}}$ & Intercept $b_{\mathrm{r}}$ & $R^{2}$ & $P$ \\
\hline \multicolumn{5}{c}{ PCDD/Fs } \\
Site A & -0.62 & -5.02 & 0.60 & $<0.0001$ \\
Site B & -0.46 & -4.73 & 0.36 & $<0.0001$ \\
Site C & -0.64 & -5.11 & 0.45 & $<0.0001$ \\
\hline & & PCBs & & \\
Site A & -0.97 & -6.05 & 0.81 & $<0.0001$ \\
Site B & -0.76 & -5.28 & 0.74 & $<0.0001$ \\
Site C & -0.75 & -5.51 & 0.74 & $<0.0001$ \\
\hline & & PBDEs & & \\
Site A & -0.56 & -6.14 & 0.36 & $2.86 \times 10^{-4}$ \\
Site B & -0.44 & -5.99 & 0.17 & 0.019 \\
Site C & -0.64 & -6.53 & 0.39 & $1.34 \times 10^{-4}$ \\
\hline
\end{tabular}

reported the temperature dependent $P_{\mathrm{L}}{ }^{0}$ of $\mathrm{PCDD} / \mathrm{Fs}$ by correlating the $P_{\mathrm{L}}{ }^{0}$ with gas chromatographic retention indexes (RI) ${ }^{[16-18]}$, i.e. $\log P_{\mathrm{L}}{ }^{0}=-1.34 R I / T+1.67 \times 10^{-3} R I$ $-1320 / T$. The changes in vapor pressures of PBDEs with temperature were described by an integrated ClausiusClapeyron equation in the form of $\log P_{\mathrm{L}}{ }^{0}=B / T+A^{[19]}$. The vapor pressures of $\mathrm{PCBs}$ can be correlated with temperature in a similar equation to $\mathrm{PBDEs}^{[20]}$. In this study, we also use these methods to obtain the subcooled vapor pressures of $\mathrm{PCDD} / \mathrm{Fs}, \mathrm{PCBs}$ and $\mathrm{PCDD} / \mathrm{Fs}$ at the average temperature of $17^{\circ} \mathrm{C}$ during the sampling period. The average PM10 data of $90 \mu \mathrm{g} / \mathrm{m}^{3}$ was used because TSP was not routinely measured. PCBs in site A ap- 
peared approach equilibrium. However, other slopes were shallower than -1 , indicating disequilibrium for the three groups of chemicals. PCBs were more close to equilibrium than PCDD/Fs and PBDEs, which can be explained by the fact that PCBs were mainly associated with gas phases as discussed earlier. Different to PCBs, PCDD/Fs and PBDEs in sites A and $\mathrm{C}$ were more close to equilibrium than that at site $\mathrm{B}$ due to less traffic influences.

\subsection{Comparison of partitioning models}

Two different sorption models have been proposed and successfully used to describe the atmospheric gas-particle partitioning of SVOCs. One is Junge-Pankow model $^{[21,22]}$, which is based on linear Langmuir isotherm. It relates the particulate fraction of chemicals with the subcooled liquid vapor pressure of the compound and the particle surface area, as shown in the following equation:

$$
\varphi=\frac{c \theta}{P_{\mathrm{L}}^{0}+c \theta}
$$

where $\varphi$ is the fraction of the total atmospheric concentration that is sorbed on the particulate matter. The parameter $c$ is a constant that based on the heat of desorption from the particle surface, the heat of vaporization of the compound, and the moles of adsorption sites on the aerosol. An empirical value of $0.172 \mathrm{~Pa} \cdot \mathrm{m}$ is typically used although it may vary with the class of compound. $\theta$ is the aerosol surface area and ranges from $4.2 \times 10^{-5}$ for clean continental background, $1.5 \times 10^{-4}$ for rural area, and $1.1 \times 10^{-3} \mathrm{~cm}^{2} \mathrm{~cm}^{-3}$ for urban area ${ }^{[23]}$.

Figure 3 compares the particulate fractions $(\varphi)$ of PCDD/Fs, PCBs and PBDEs predicted by JungePankow model with the average measured data. The measured $\varphi$ was calculated using the ambient concentrations in the particle phase divided by the total ambient concentrations (gas + particle). Although the measured $\varphi$ was close to the urban partitioning curve, the JungePankow model tended to underestimate the particulate sorption of $\mathrm{PCDD} / \mathrm{F}$ congeners. This result was contradicted with data reported in the literature ${ }^{[7]}$. The predicted urban curve fitted well with the measured PCBs in site $\mathrm{A}$ and $\mathrm{C}$ whereas it slightly underestimated the particulate sorption in site B due to the traffic perturbations. As seen from Figure 3(c), Junge-Pankow model overestimated the particulate fractions of PBDEs. The derivation between the modeling and the measured data was due to the different $c$ values for different com-
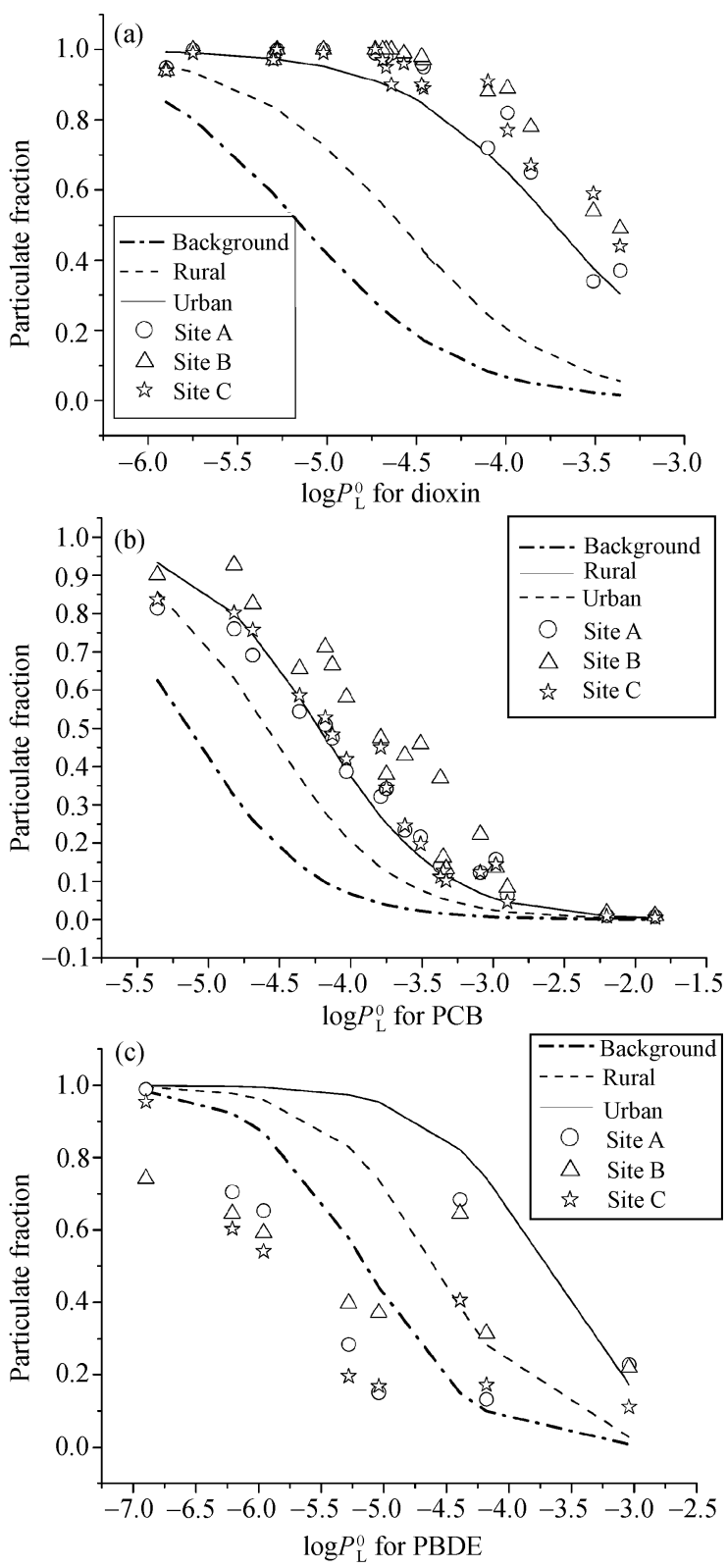

Figure 3 Comparsion between predictions from Junge-Pankow model and measurements.

pounds and aerosol types ${ }^{[7]}$. The parameter value used in literature may not be appropriate for the E-waste site.

Another partitioning model was $K_{\text {oa }}$ absorption model $^{[24]}$ that requires knowledge of $K_{\text {oa }}$ and the organic matter fraction $\left(f_{\text {om }}\right)$ of the aerosol which are more easily measurable than the parameters of the Junge-Pankow model, i.e. $\log K_{\mathrm{p}}=\log K_{\mathrm{oa}}+\log f_{\mathrm{om}}-11.91$, The fraction on particles is then calculated from $K_{\mathrm{p}}$ and TSP by

$$
\varphi=\frac{K_{\mathrm{p}} \mathrm{PM} 10}{1+K_{\mathrm{p}} \mathrm{PM} 10} .
$$

Figure 4 compares the predicted and measured $\varphi$ by 

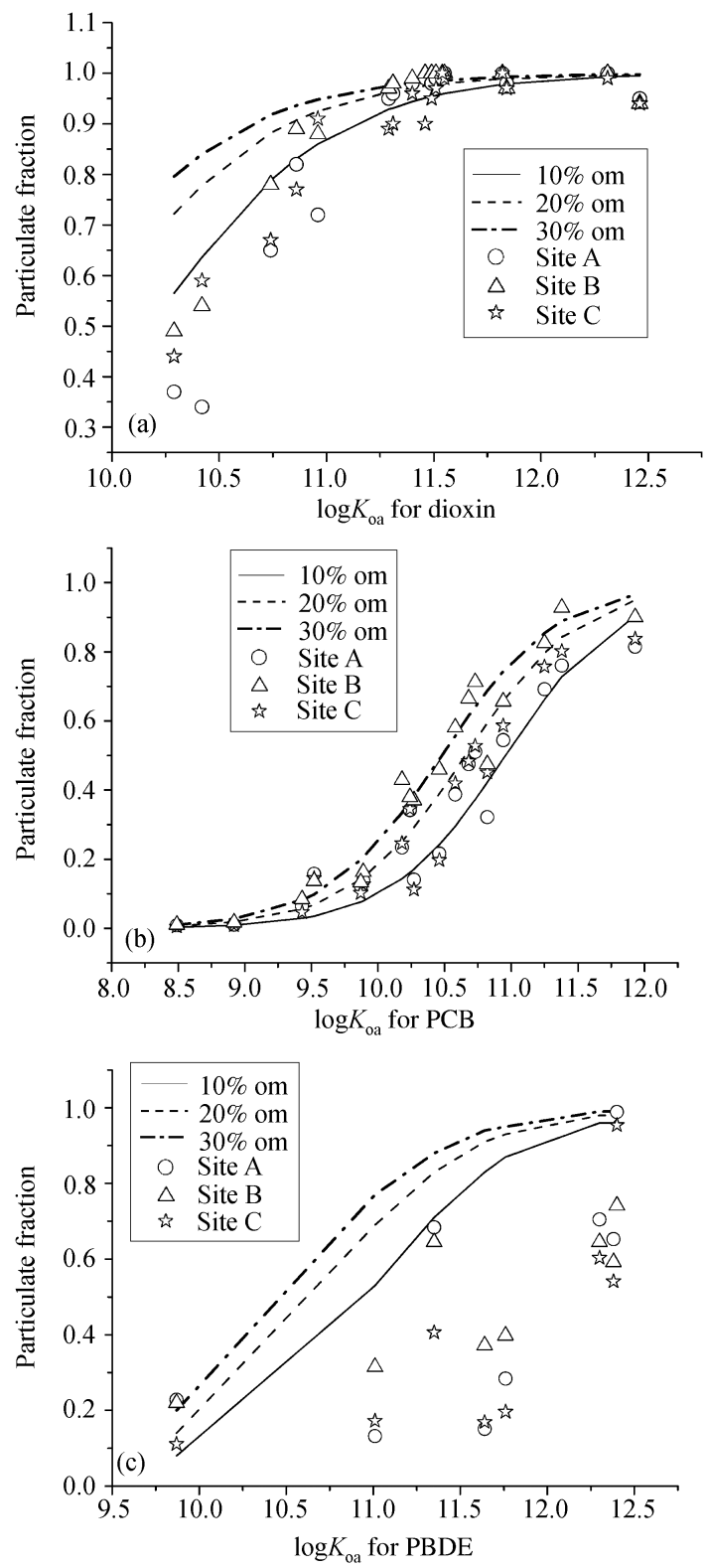

Figure 4 Comparsion between predictions from $K_{\text {oa }}$ absorption model and measurements. om, Organic matter.

1 Kouimtzis T H, Samara C, Voutsa D, et al. PCDD/Fs and PCBs in air borne particulate matter of the greater Thessaloniki area, N. Greece. Chemosphere, 2002, 47(2): 193-205

2 Yu L P, Mai B X, Meng X Z, et al. Particle-bound polychlorinated dibenzo- $p$-dioxins and polychlorinated dibenzofurans in the atmosphere of Guangzhou, China. Atmos Environ, 2006, 40(1): 96-108

3 Chen L G, Mai B X, Bi X H, et al. Concentration levels, compositional profiles, and gas-particle partitioning of polybrominated diphenyl ethers in the atmosphere of an urban city in South China. Environ Sci Technol, 2006, 40(4): 1190-1196

4 Chu S G, Tong Y P. Polychlorinated biphenyl congener residues in sediment and soil from pollution areas. China Environ Sci (in Chi- model consisting of $10 \%, 20 \%$, and $30 \%$ organic matter in the particulates. The $K_{\text {oa }}$ values for PCDD/Fs were correlated with published retention time indices at the average temperature of $17^{\circ} \mathrm{C}$, i.e. $\log K_{\mathrm{oa}}=a+b(\mathrm{RTI})^{[25]}$. The temperature dependent values for PCBs were calculated based on the method that correlated $\log K_{\text {oa }}$ with $\log P_{\mathrm{L}}{ }^{0}{ }^{[26]}$. The $K_{\mathrm{oa}}$ values for PBDEs were obtained by correlating $\log K_{\text {oa }}$ with reversal temperatures ${ }^{[27]}$. The $K_{\text {oa }}$ model well estimated the particulate sorptions of $\mathrm{PCDD} / \mathrm{Fs}$. The lower chlorinated PCDD/Fs (log$\left.K_{\text {oa }}<10.5\right)$ were generally close to the partitioning predicted by $10 \%$ organic matter in the aerosols, while the higher chlorinated congeners $\left(\log K_{\text {oa }}>10.5\right)$ were close to those consisting of $20-30 \%$ organic matters. The measured PCBs in sites A and C presented between the predicted partitioning curves consisting $10 \%$ and $20 \%$ organic matter, whereas PCBs in site B were close to the prediction curve consisting $10 \%$ organic matter. The $K_{\text {oa }}$ model overestimated the particulate fractions of PBDEs, which should be further investigated.

\section{Conclusions}

In this study, PCDD/Fs, PCBs and PBDEs in the ambient air of Taizhou were measured. The concentrations of the three groups of pollutants were higher than other urban sites. The lighter congeners of these pollutants were found mainly in the gas phase, whereas the heavier congeners were dominantly presented in the particle phase. For the three sampling sites, the atmospheric pollutants did not reach gas-particle equilibrium. The pollution sources for the three groups of POPs should be further investigated.

nese), 1995, 15(4): 423-432

5 Luo Y M, Teng Y, Li Q B, et al. Soil environmental quality and remediation in Yangtze River delta region: 1. composition and pollution of polychlorinated dibenzo- $p$-dioxins and dibenzofurans (PCDD/ Fs) in a typical farm land. Acta Pedol Sin (in Chinese), 2005, 42(4): $570-576$

6 Liu H X, Zhang Q H, Cai Z W, et al. Separation of polybrominated diphenyl ethers, polychlorinated biphenyls, polychlorinated diebenzo$p$-dioxins and dibenzo-furans in environmental samples using silica gel and florisil fractionation chromatography. Anal Chim Acta, 2006, 557(1-2): 314-320

7 Lee R G, Jones K C. Gas-particle partitioning of atmospheric 
PCDD/Fs: Measurements and observations on modeling. Environ Sci Technol, 1999, 33(20): 3596-3604

8 Lohmann R, Jones K C. Dioxins and furans in air and deposition: A review of levels, behaviour and processes. The Sci Total Environ, 2000, 219(1): 53-81

9 Van den Berg M, Birnbaum L, Bosveld ATC, et al. Toxic equivalency factors (TEFs) for PCBs, PCDDs, PCDFs for humans and wildlife. Environ Health Perspect, 1998, 106: 775-792

10 Kim K S, Masunaga S. Behavior and source characteristic of PCBS in urban ambient air of Yokohama, Japan. Environ Pollut, 2005, 138(2): $290-298$

11 Tasdemir Y, Vardar N, Odabasi M, et al. Concentrations and gas/particle partitioning of PCBs in Chicago. Environ Pollut, 2004, 131(1): $35-44$

12 Hoh E, Hites R A. Brominated flame retardants in the atmosphere of the east-central United States. Environ Sci Technol, 2005, 39(20): $7794-7802$

13 Correa O, Rifai H, Raun L, et al. Concentrations and vapor-particle partitioning of polychlorinated dibenzo- $p$-dioxins and dibenzofurans in ambient air of Houston, TX. Atmos Environ, 2004, 38(39): $6687-6699$

14 Finzio A, Mackay D, Bidleman T. Octanol-air partition coefficient as a predictor of partitioning of semi-volatile organic chemicals to aerosols. Atmos Environ, 1997, 31(15): 2289-2296

15 Pankow J F. An absorption model of gas/particle partitioning of organic compounds in the atmosphere. Atmos Environ, 1994, 28(2): $185-188$

16 Eitzer B D, Hites R A. Vapor pressures of chlorinated dioxins and dibenzofurans. Environ Sci Technol, 1988, 22(11): 1362-1364

17 Eitzer B D, Hites R A. Polychlorinated dibenzo- $p$-dioxins and dibenzofurans in the ambient atmosphere of Bloomington, Indiana. Environ Sci Technol, 1989, 23(11): 1389-1395
18 Hung H, Blanchard P, Poole G, et al. Measurement of particle-bound polychlorinated dibenzo- $p$-dioxins and dibenzofurans (PCDD/Fs) in Arctic air at Alert, Nunavut, Canada. Atmos Environ, 2002, 36(6): $1041-1050$

19 Tittlemier S A, Halldorson T, Stern G A, et al. Vapor pressures, aqueous solubilities, and Henry's law constants of some brominated flame retardants. Environ Toxicol Chem, 2002, 21(9): 1804-1810

20 Falconer R L, Bidleman T F. Vapor pressures and predicted particle/gas distributions of pcb congeners as functions of temperature and ortho-chlorine substitutuions. Atmos Environ, 1994, 28(3): 547-554

21 Junge C E. Basic considerations about trace constituents in the atmosphere as related to the fate of global pollutants. In: Suffet I H, ed. Fate of Pollutants in the Air and Water Environments. Part I. New York: Wiley-Interscience, 1977. 7-26

22 Pankow J F. Review and comparative analysis of the theories on partitioning between the gas and aerosol particulate phases in the atmosphere. Atmos Environ, 1987, 21(11): 2275-2283

23 Bidleman T F. Atmospheric processes: Wet and dry deposition of organic compounds controlled by their vapor-particle partitioning. Environ Sci Technol, 1988, 22(4): 361-367

24 Harner T, Bidleman T F. Octanol-air partition coefficient for describing particle/gas partitioning of aromatic compounds in urban air. Environ Sci Technol, 1998, 32(10): 1494-1502

25 Harner T, Green N L, Jones K C. Measurements of octanol-air partition coefficients for PCDD/Fs: A tool in assessing air-soil equilibrium status. Environ Sci Technol, 2000, 34(15): 3109-3114

26 Harner T, Bidleman T F. Measurements of octanol-air partition coefficients for polychlorinated biphenyls. J Chem Eng Data, 1996, 41(4): $895-899$

27 Harne T, Shoeib S. Measurements of octanol-air partition coefficients $\left(K_{\mathrm{OA}}\right)$ for ploybrominated diphenyl ethers (PBDEs): Predicting partitioning in the environment. J Chem Eng Data, 2002, 47(2): 228 - 232 